\title{
Corrigendum: Cooper et al, Subtotal Gastrectomy as "Last Resort" Consideration in the Management of Refractory Rumination Syndrome
}

\author{
Chad J. Coopera, c, Salman Otoukesha ${ }^{\mathrm{a}}$, Mona Mojtahedzadeh ${ }^{\mathrm{b}}$, Juan M. Galvis ${ }^{\mathrm{a}}$, Richard W. McCallum ${ }^{\mathrm{a}}$
}

Corrections to article "Subtotal Gastrectomy as "Last Resort" Consideration in the Management of Refractory Rumination Syndrome", by Chad J. Cooper et al, published in Vol. 7, No. 3-4, 2014, p98-101, doi: http://dx.doi.org/10.14740/gr594w.

The authors would like to make the following corrections.

In Abstract section, the sentence "On subsequent follow-up visits over a 6-month course, the refractory nausea and vomiting had resolved by more than $85 \%$ with and improvement in her BMI and quality of life." should read "On subsequent follow-up visits over a 4-month course, the refractory nausea and vomiting had resolved by more than $70 \%$ with and improvement in her nutritional status and quality of life."

In the last paragraph of Case Report section, the sentence "On subsequent follow-up visits over a 6-month course, the refractory nausea and vomiting had resolved by more than $85 \%$ with and improvement in her BMI and quality of life." should read "On subsequent follow-up visits over a 4-month course, the refractory nausea and vomiting had resolved by more than $70 \%$ with and improvement in her nutritional status and quality of life."

\footnotetext{
Manuscript accepted for publication August 09, 2014

${ }^{a}$ Department of Internal Medicine, Texas Tech University Health Sciences Center, El Paso, Texas, USA

bDepartment of Psychiatry, Texas Tech University Health Sciences Center, El Paso, Texas, USA

${ }^{\mathrm{c} C o r r e s p o n d i n g ~ A u t h o r: ~ C h a d ~ J . ~ C o o p e r, ~ D e p a r t m e n t ~ o f ~ I n t e r n a l ~ M e d i c i n e, ~}$ Texas Tech University Health Sciences Center, 4800 Alberta Ave, El Paso, TX 79905, USA. Email: chad.cooper@ttuhsc.edu
}

doi: http://dx.doi.org/10.14740/gr624e

Articles $\left(\right.$ The authors | Journal compilation $@$ Gastroenterol Res and Elmer Press Inc ${ }^{\mathrm{TM}}$ | www.gastrores.org

This is an open-access article distributed under the terms of the Creative Commons Attribution License, which permits unrestricted use, distribution, and reproduction in any medium, provided the original work is properly cited 